\title{
THE EFFECT OF A CRACKED TOOTH ON THE DYNAMIC RESPONSE OF A SIMPLE GEARBOX WITH A FLEXIBLE COUPLING UNDER ACYCLISM OPERATION
}

\author{
Ahmed Hammami, Atef Hmida, Fakher ChaAri, \\ Mohamed Taoufik Khabou, Mohamed Haddar \\ Mechanics, Modeling and Production Laboratory, National Engineering School of Sfax, Sfax, Tunisia \\ e-mail: ahmed.hammami2109@gmail.com; abdallahatef@yahoo.fr; fakher.chaari@gmail.com; \\ mtkhabou@hotmail.com; mohamed.haddar@enis.rnu.tn
}

\begin{abstract}
In this paper, the effect of a cracked tooth on the dynamic response of a simple gearbox with a flexible coupling is studied. The gearbox is driven by a combustion engine through a flexible coupling for which Nelson and Crandall's model is used. The acyclism regime is generated by diesel engine inducing fluctuations of speed, torque and meshing stiffness. In addition, the cracked tooth of the wheel gear is modelled by lowering the meshing stiffness. After solving the equations of motion by using the Newmark method, the time response, spectrum, joint time-frequency analysis and envelope spectrum are used to characterize the dynamic response of the defected gearbox where the cracked tooth frequency is irregular and independent of the acyclism frequency.
\end{abstract}

Keywords: acyclism, cracked spur gearbox, dynamic behavior, elastic coupling

\section{Introduction}

Gear transmissions are often used to transmit torque and rotational movement generated by a driving motor to a receiver. They are frequently running under severe conditions causing dynamic problems. Many research investigations focused on the dynamics of gear transmissions such as Bartelmus (2001) who studied the effect of clutch damping on the dynamic factor of a gear transmission. In addition, tooth contact conditions and backlash effects on chaotic vibrations of a simple gearbox were highlighted by Łuczko (2008). Hammami et al. (2015) carried out an impact test applied to a planetary gear box with power recirculation in order to characterize its modal properties.

Gear transmissions can be driven by a combustion engine running under a transient regime called acyclism. Many researchers have focused on this acyclism regime. We can cite Barthod et al. (2007a) who investigated the dynamic and the acoustic behavior of different kinds of gearboxes running under the acyclism regime. Sika and Velex (2008) used a torsional gear model to study the effect of the variable speed of an engine which was modeled through a multi-harmonic function. A spur gear driven by a diesel engine was also investigated by Khabou et al. (2011) who used an approximate formula to compute the engine torque for the case of unknown pressure inside cylinders. Hmida et al. (2018) used the same approximation of the engine torque and they studied the effect of eccentricity localized in the wheel gear on the dynamic response of the mechanical system composed by a diesel engine, elastic coupling and a spur gearbox. The loose gear is a common phenomenon in an automotive gearbox, it depends on the level of acyclism and the loose gear inertia, and it generates rattle noise. Baudin et al. (2016) studied this behavior and exploited an angle/time cyclo-stationary approach and the order/frequency spectrum to study backlashes of gears during run-up. 
Gear transmissions are also excited through inevitable defects such as cracked teeth, which is at the origin of teeth contact loss as well as reduction of gear mesh stiffness leading to apparition of sidebands around meshing frequencies and their harmonics as mentioned by Chaari et al. (2009), Driss et al. (2014) and Ma et al. (2015). The cracked tooth can be a distributed defect. This kind of defect was studied by Fakhfakh et al. (2005) who noticed an increase in both the signal amplitude and spectral component in stationary conditions through simulation and experimental tests.

Many researchers studied also the effects of different crack levels on gear mesh stiffness, see Chaari et al. (2009). Later, Ma et al. (2014) proposed an improved mesh stiffness model which characterized depth, width, initial position and crack propagation direction of a tooth. They correlated firstly this model with the finite element method and then the numerical dynamic behavior in stationary conditions with experiments. In addition, Saxena et al. (2017) studied the effect of mesh stiffness of a healthy and cracked gear tooth on the modal and frequency response of a geared rotor system which was modelled using Timoshenko beam elements. In order to classify tooth defects like spall and crack faults, Park et al. (2018) applied the Ensemble Empirical Mode Decomposition to the measured transmission error which was correlated with the simulated transmission error obtained from the Finite Element Method.

Gear transmission can be integrated in a drive train with the engine, clutch and disc brake. Ghorbel et al. (2018) proposed a dynamic model of the drive train taking into account nonlinear dry friction of the clutch. They supposed that the speed and the load of the engine were stationary and they studied effects of tooth defects (tooth local fault and tooth profile error) on the dynamic response in time and frequency domains. In fact, the level of the time signal increases in the case of the profile error, and sidebands appear in the frequency domain in the case of a tooth local fault.

In this work, the studied system is composed of a cracked gearbox which is driven by a diesel engine and connected through an elastic coupling for which a model proposed by Nelson and Crandall (1992) is selected. Excitations induced by torque and speed fluctuations of the diesel engine from one side and the cracked tooth of the spur gearbox are considered by a numerical model. The combustion engine torque is computed taking into account the variation of pressure inside cylinders, and a particular case of the cracked tooth in the wheel gear where the gear meshing frequency is variable and the greatest common divisor between the number of tooth of the pinion and the gear is equal to one. In this case, the frequency of the defect is independent of the frequency of acyclism and it is variable in time. The dynamic response in these conditions is computed using the Newmark method, and the results are shown using joint time-frequency analysis and the envelope spectrum of acceleration signals.

\section{Model and equation of motion of a simple gearbox with a flexible coupling}

In the studied mechanical system, the mechanical power delivered by the diesel engine is transmitted to the receiver through a flexible coupling and a cracked tooth gearbox. These components are assumed rigid and they are connected through three shafts which are carried by three bearings.

In the dynamic model (Fig. 1), each shaft is stressed by torsion, and it is modeled by torsional stiffness $K_{\theta i}$ and torsional damping $C_{\theta i}(i=1,2,3)$. The translation motion of the bearings is modeled with springs $\left(K_{x i}, K_{y i}\right)$ and damping $\left(C_{x i}, C_{y i}\right)$. In the gearbox, the gearing between the pinion and the wheel is presented by the mesh stiffness $K_{m}$ and the mesh damping $C_{g m}$.

The model proposed by Nelson and Crandall (1992) is selected for the coupling because it is the supremacist model to describe the behavior of the flexible coupling (Tadeo et al., 2011). This coupling is considered by two disks connected through two translation stiffnesses $\left(K_{x c}, K_{y c}\right)$, a 


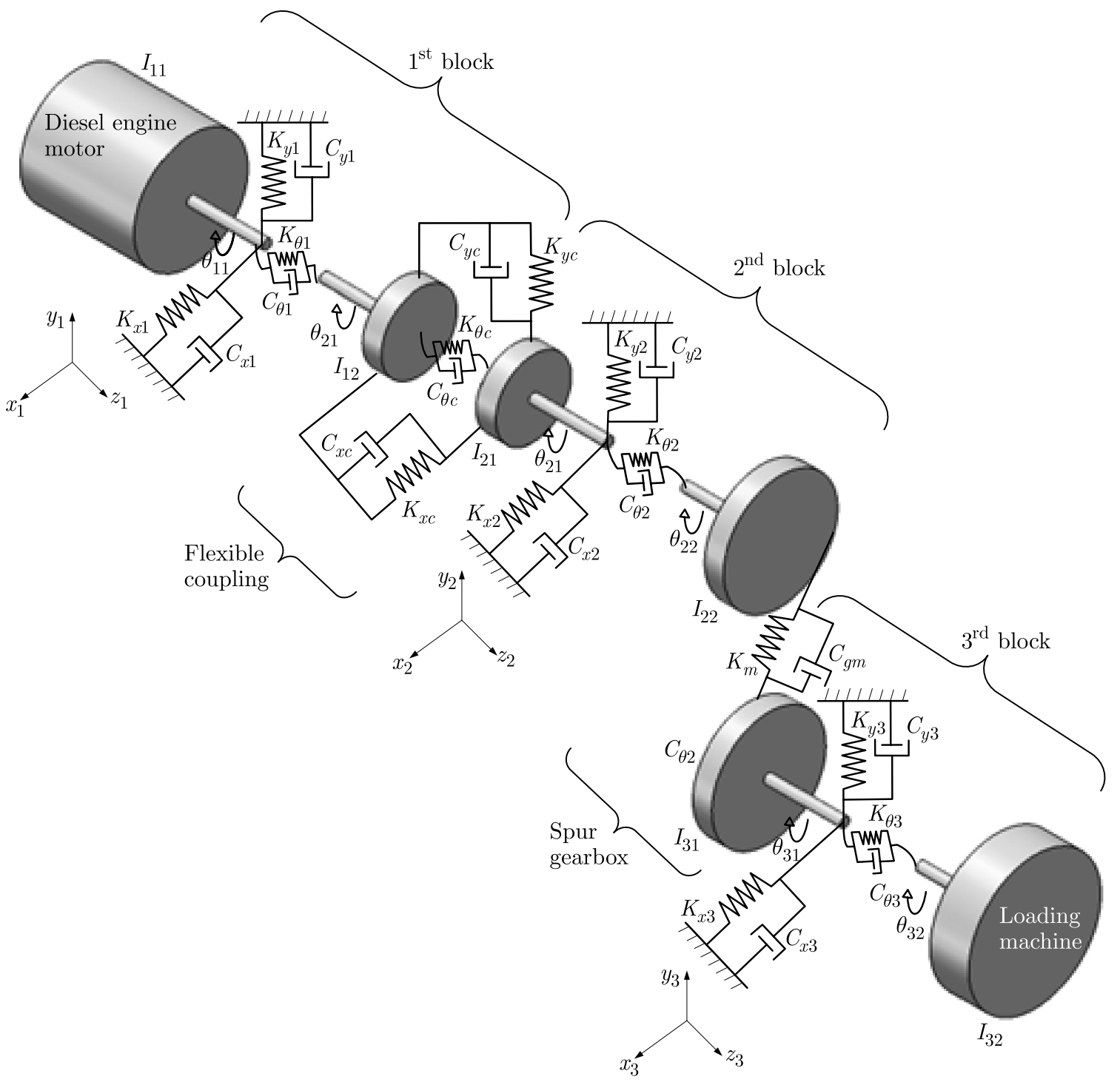

Fig. 1. Model of the simple gearbox with a flexible coupling

torsional stiffness $K_{\theta c}$, two translation dampings $\left(C_{x c}, C_{y c}\right)$ and a torsional damping $C_{\theta c}$. Inertial effects of the coupling are included in the first $I_{12}$ and the second block $I_{21}$.

This dynamical model is composed of three blocks as shown in Fig. 1.

The equation of motion of the proposed model is derived using Lagrange's formalism

$$
\mathbf{M} \ddot{\mathbf{q}}+\left(\mathbf{C}_{m e s h}+\mathbf{C}_{s}\right) \dot{\mathbf{q}}+\left[\mathbf{K}(t)+\mathbf{K}_{s}\right] \mathbf{q}=\mathbf{F}(t)
$$

where $\mathbf{q}$ is the vector containing degrees of freedom of the system

$$
\mathbf{q}=\left[\theta_{11}, \theta_{12}, \theta_{21}, \theta_{22}, \theta_{31}, \theta_{32}, x_{1}, y_{1}, x_{2}, y_{2}, x_{3}, y_{3}\right]
$$

and $\mathbf{M}$ is the mass matrix, $\mathbf{K}_{s}$ and $\mathbf{K}(t)$ are the stiffness matrices of the structure and gear meshing, $\mathbf{C}_{s}$ and $\mathbf{C}_{\text {mesh }}$ are the damping matrices of the structure and gear meshing, $\mathbf{F}(t)$ is the loading vector.

The gyroscopic effect is neglected since the engine regime is low $(N=1000 \mathrm{rpm})$.

Readers can refer to Hmida et al. (2017) for details concerning these matrices. 


\section{Numerical simulations}

In this Section, the effect of the acyclism and cracked tooth are introduced into the model. The parameters of the model are given in Table 1.

Table 1. Parameters of the model

\begin{tabular}{|c|c|}
\hline \multicolumn{2}{|l|}{ Parameters of the gearbox } \\
\hline Number of teeth $[-]$ & 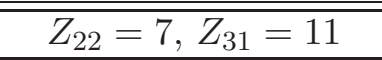 \\
\hline Mass $[\mathrm{kg}]$ & $M_{22}=1.77, m_{31}=2.5$ \\
\hline Pressure angle $\left[^{\circ}\right]$ & $\alpha=20$ \\
\hline Teeth module $[\mathrm{m}]$ & $m_{n}=5 \cdot 10^{-3}$ \\
\hline Contact ratio $[-]$ & $\varepsilon_{\alpha}=1.33$ \\
\hline Average mesh stiffness $[\mathrm{N} / \mathrm{m}]$ & $K_{\text {moy }}=7.175 \cdot 10^{7}$ \\
\hline \multicolumn{2}{|l|}{ Coupling characteristics } \\
\hline Inertia $\left[\mathrm{kg} \mathrm{m}^{2}\right]$ & $4 \cdot 10^{-3}$ \\
\hline Mass $[\mathrm{kg}]$ & 4.5 \\
\hline Torsional stiffness of coupling $[\mathrm{Nm} / \mathrm{rad}]$ & 352 \\
\hline Translation stiffness of coupling $[\mathrm{N} / \mathrm{m}]$ & $462 \cdot 10^{2}$ \\
\hline \multicolumn{2}{|c|}{ Characteristics of the engine motor } \\
\hline Inertia $\left[\mathrm{kg} \mathrm{m}^{2}\right]$ & $\overline{4 \cdot 10^{-3}}$ \\
\hline Length of the connecting rod $L[\mathrm{~mm}]$ & 138 \\
\hline Radius of the crank $R[\mathrm{~mm}]$ & 40 \\
\hline Piston stroke $[\mathrm{mm}]$ & 80 \\
\hline Alternative mass $[\mathrm{kg}]$ & 0.6 \\
\hline Cylinders number $[-]$ & 4 \\
\hline Cylinder diameter $\emptyset[\mathrm{mm}]$ & 92 \\
\hline Unit cylinder capacity $V_{c y l}\left[\mathrm{~cm}^{3}\right]$ & 562 \\
\hline Engine regime $N[\mathrm{rpm}]$ & 1000 \\
\hline Maximum pressure inside cylinders $P_{\max }[\mathrm{bar}]$ & 24 \\
\hline Crank angle for maximum pressure $\left[{ }^{\circ}\right]$ & 380 \\
\hline \multicolumn{2}{|l|}{ Receiver characteristics } \\
\hline Inertia $\left[\mathrm{kg} \mathrm{m}^{2}\right]$ & $6 \cdot 10^{-3}$ \\
\hline \multicolumn{2}{|c|}{ Shafts and bearings parameters } \\
\hline Torsional stiffness of shafts $[\mathrm{Nm} / \mathrm{rad}]$ & 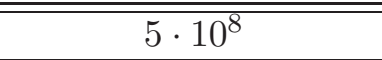 \\
\hline Stiffness of bearing $[\mathrm{N} / \mathrm{m}]$ & $5 \cdot 10^{8}$ \\
\hline
\end{tabular}

\subsection{Effect of acyclism}

During the power stroke, the speed and torque generated by a diesel engine are variable.

The angular speed of the diesel engine $\Omega(t)$ is a multi-harmonic function as shown in Fig. 2 (Sika and Velex, 2008).

The multi-harmonic evolution of the angular speed of the diesel engine generates a cyclic fluctuation of the gear mesh function as shown in Fig. 3.

The combustion engine develops a torque $T_{c e}$ which is the sum of the moment of combustion $T_{v g}$ and the moment of inertia of the engine inertia $T_{v i}$ (Ligier and Baron, 2002)

$$
T_{c e}=T_{v g}+T_{v i}
$$




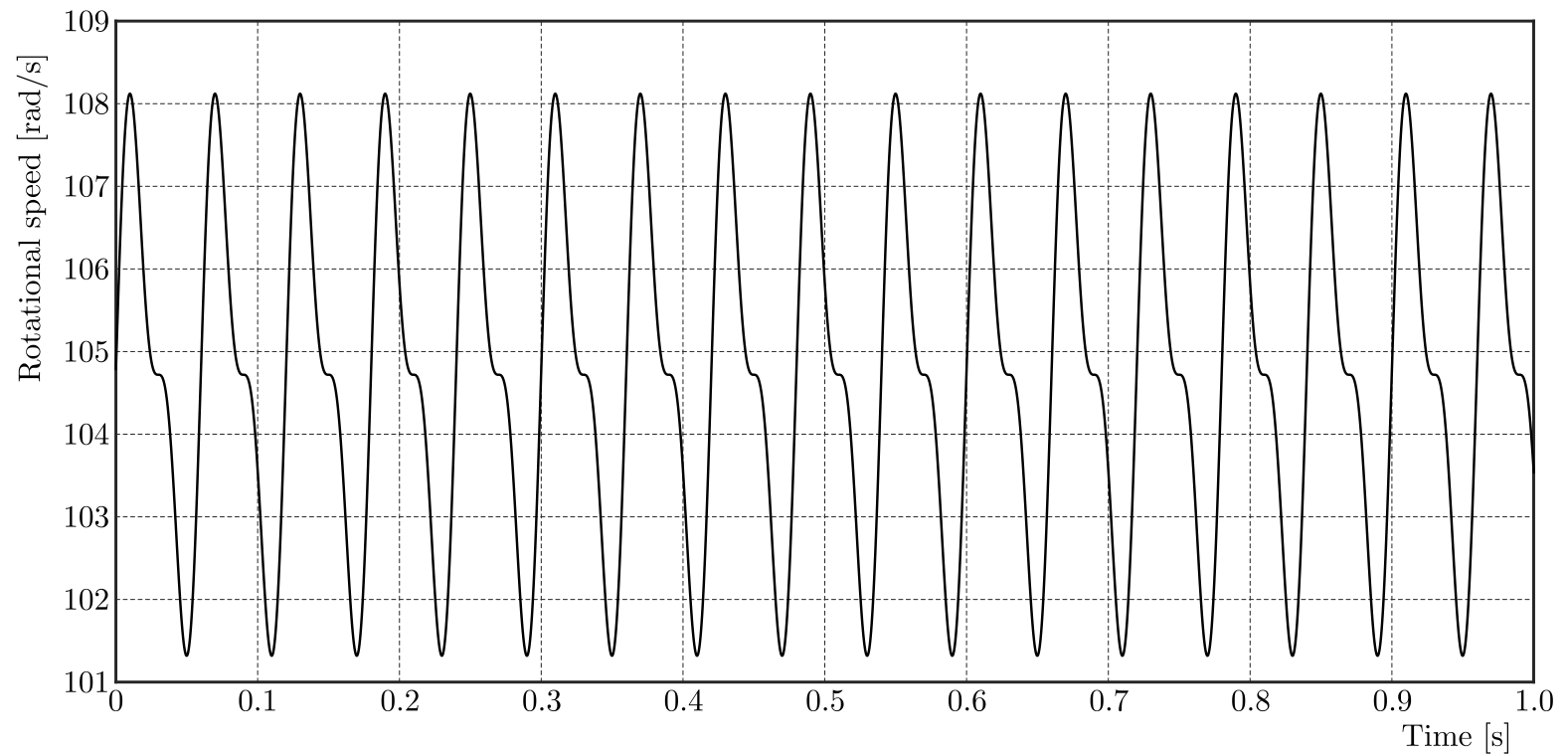

Fig. 2. Multi-harmonic evolution of the angular speed of the diesel engine
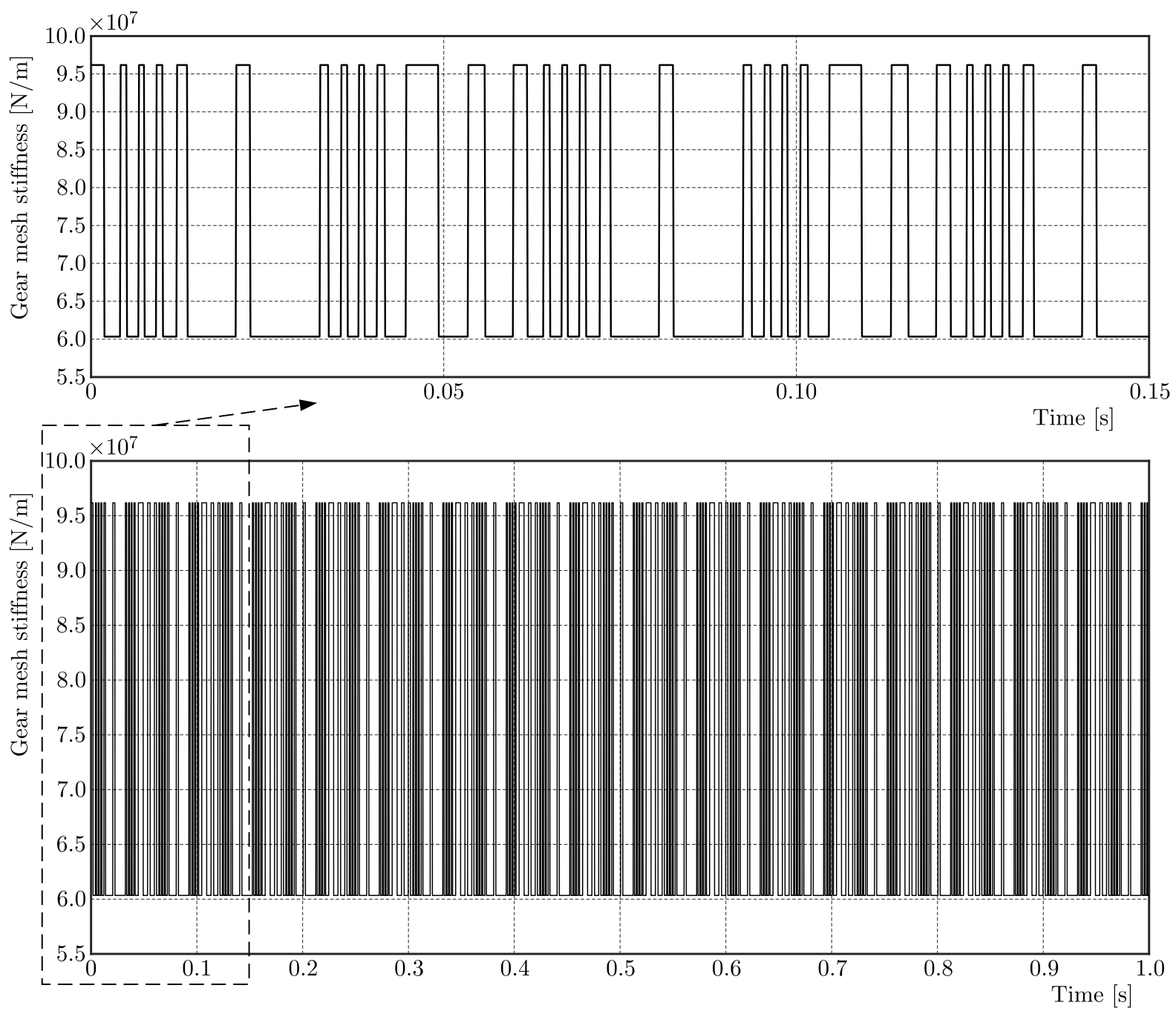

Fig. 3. Cyclic function of the mesh stiffness 
The moment of inertia of the engine inertia $T_{v i}$ is defined according to Ligier and Baron as

$$
T_{v i}=-2 m_{a l t} R^{2} \omega^{2} \sin \left(2 \alpha_{c}\right)
$$

where $\alpha_{c}$ is the crankshaft angular position, $m_{\text {alt }}$ is the alternative mass, $R$ is the radius of the crankshaft and $\omega=(2 \pi N) / 60$ is the crankshaft angular velocity.

The moment of combustion $T_{v g}$ is defined as following (Ligier and Baron, 2002)

$$
T_{v g}=-F_{g} R \sin \alpha_{c}\left(1+\frac{\cos \alpha_{c}}{\sqrt{\lambda^{2}-\sin ^{2} \alpha_{c}}}\right)
$$

with $\lambda=L / R$ is the connecting rod length to crank radius ratio, $F_{g}$ is the force applied to the piston

$$
F_{g}=\frac{\pi \emptyset^{2}}{4} P\left(\alpha_{c}\right)
$$

where $\emptyset$ is the cylinder diameter. The variation of pressure in the cylinder $P\left(\alpha_{c}\right)$ is defined as a hanning window function which reaches its maximum at $380^{\circ}$ for each cylinder since the combustion of the air/fuel mixture is not instantaneous at the Top Dead Center (TDC).

The diesel engine torque is also cyclic as shown in Fig. 4.

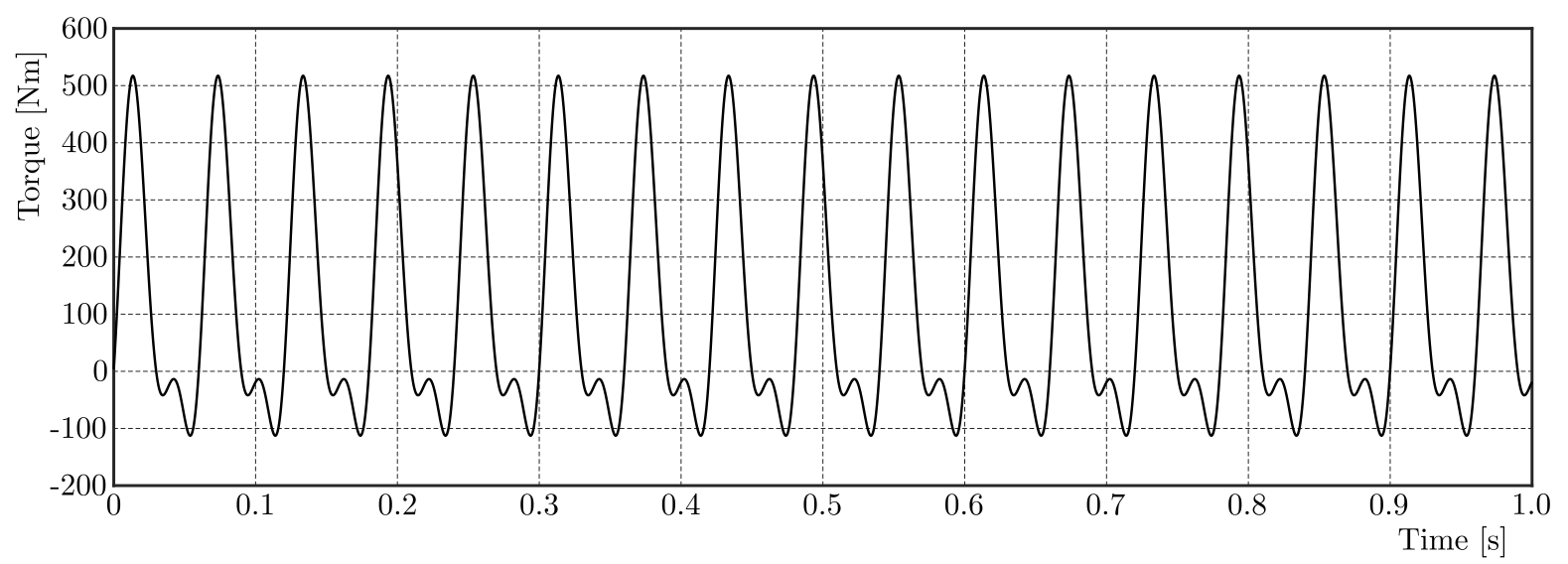

Fig. 4. Cyclic evolution of the diesel engine torque

\subsection{Effect of cracked tooth}

The approach to the modelling of the cracked tooth is based on lowering of the gear mesh stiffness as shown on the dotted circle in Fig. 5.

\subsection{Numerical results}

The Newmark method is used to solve the equation of motion of the system.

In fact, the displacement vector $\mathbf{q}_{t+\Delta t}$, the speed vector $\dot{\mathbf{q}}_{t+\Delta t}$ and the acceleration vector $\ddot{\mathbf{q}}_{t+\Delta t}$ are computed from the anterior vectors $\mathbf{q}_{t}, \dot{\mathbf{q}}_{t}$ and $\ddot{\mathbf{q}}_{t}$ by respecting these steps (Dhatt and Touzot, 1984):

1. For initial conditions, $\mathbf{q}_{t=0}, \dot{\mathbf{q}}_{t=0}$ and $\ddot{\mathbf{q}}_{t=0}$ are zero vectors

2. The coefficients $a_{i}$ are computed as following

$$
\begin{aligned}
& a=0.5 \quad a_{0}=\frac{1}{a \Delta t^{2}} \quad a_{1}=\frac{b}{a \Delta t} \\
& a_{2}=\frac{1}{a \Delta t} \quad a_{3}=\frac{1}{2 a-1} \quad a_{4}=\frac{b}{a-1} \\
& a_{5}=\frac{\Delta t}{2}\left(\frac{b}{a}-2\right) \quad a_{6}=\Delta t(1-b) \quad a_{7}=b \Delta t
\end{aligned}
$$



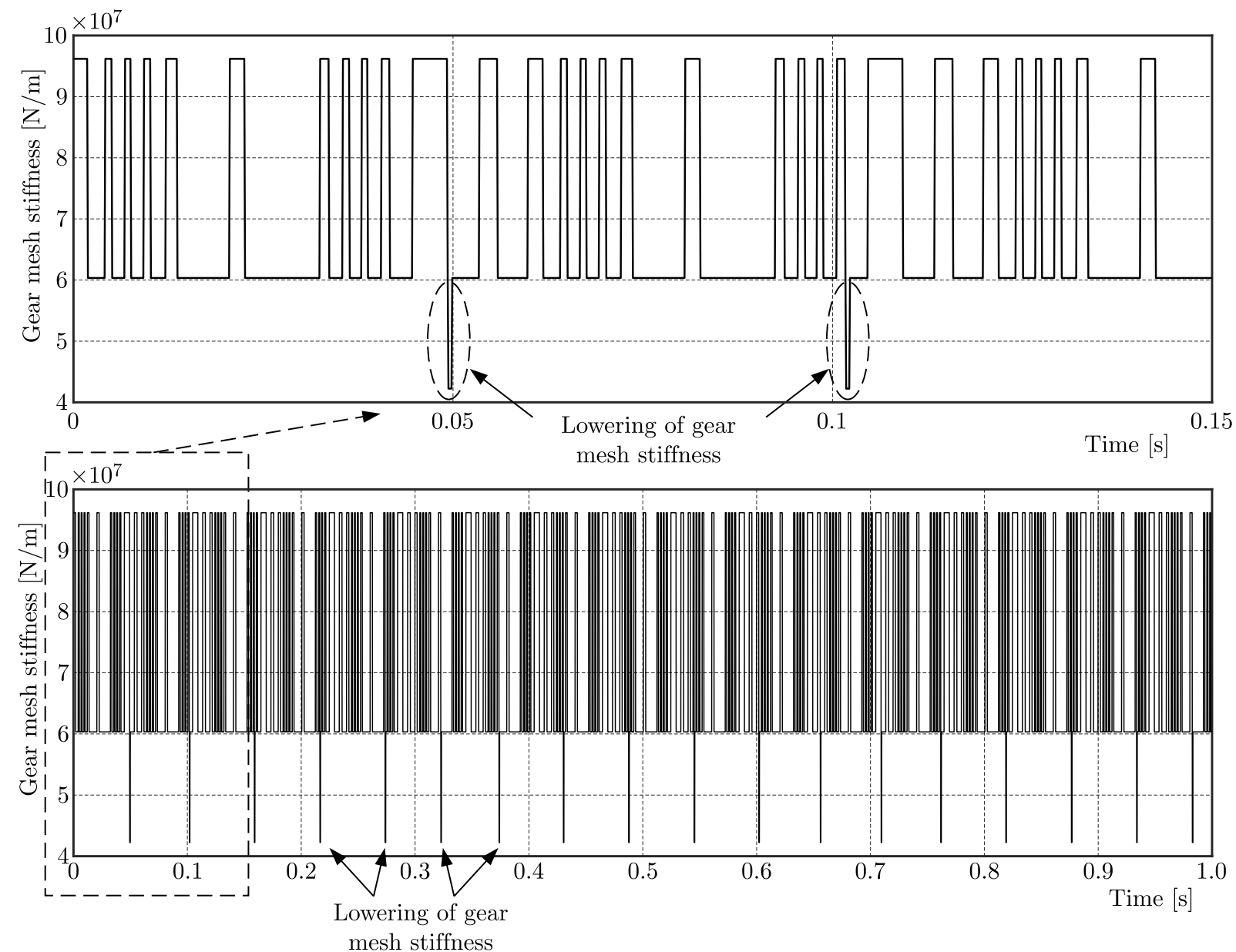

Fig. 5. Gear mesh stiffness with a cracked tooth and under acyclism
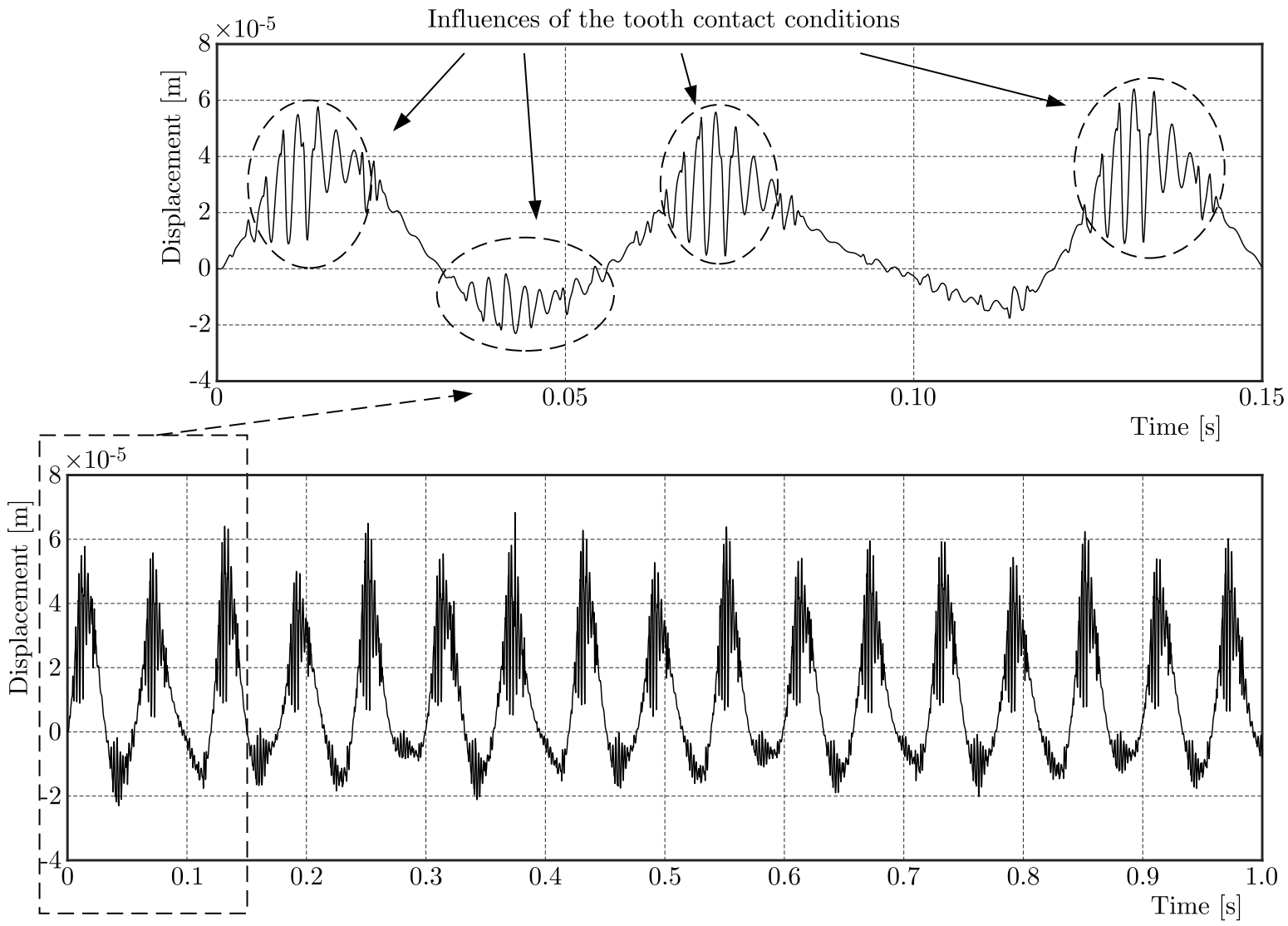

Fig. 6. Bearing displacement of the second block $\left(X_{2}\right)$ 

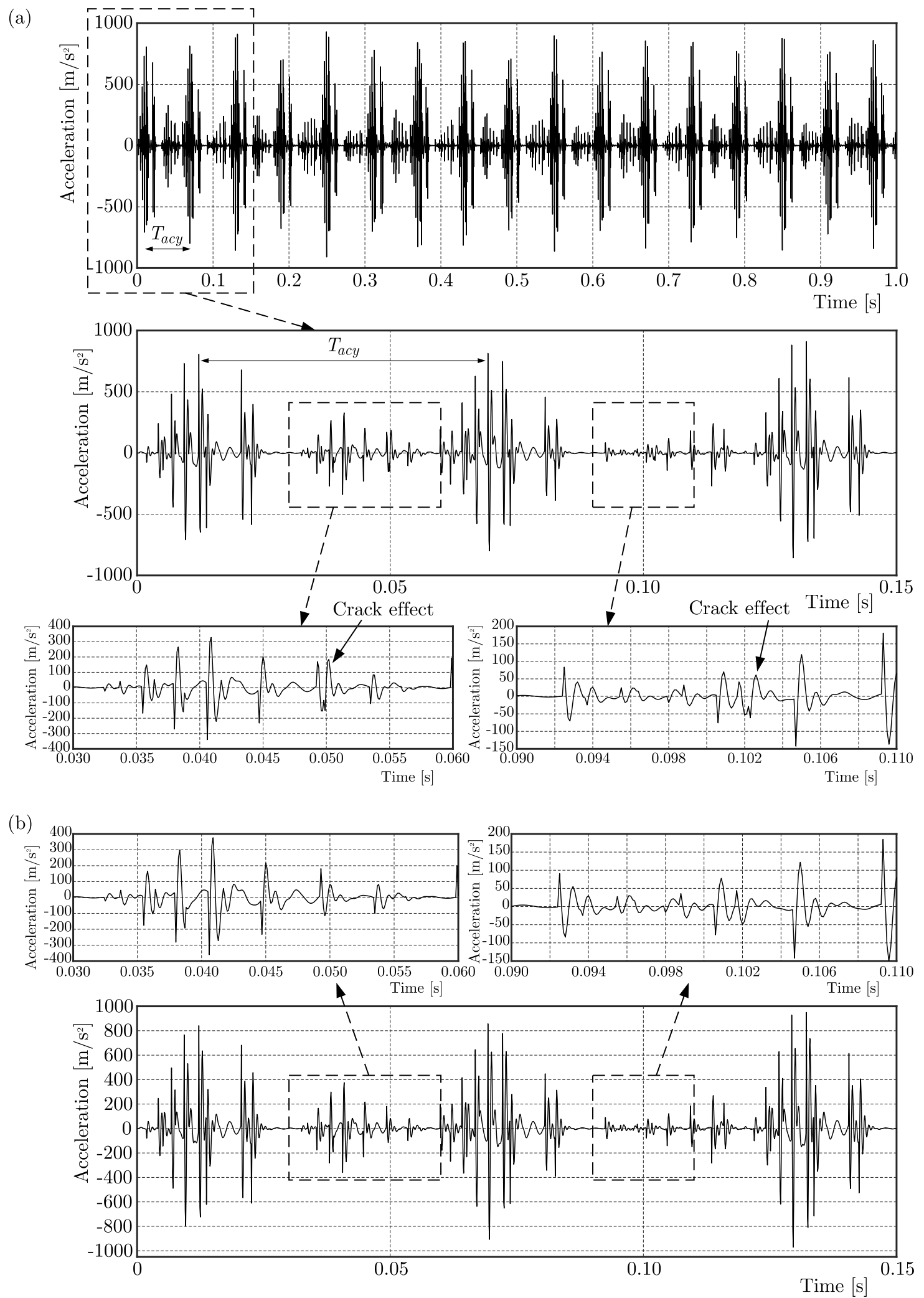

Fig. 7. Acceleration signal of the bearing of the second block (a) case study: effects of acyclism and the cracked tooth (b), healthy gearbox excited with acyclism 
(a)

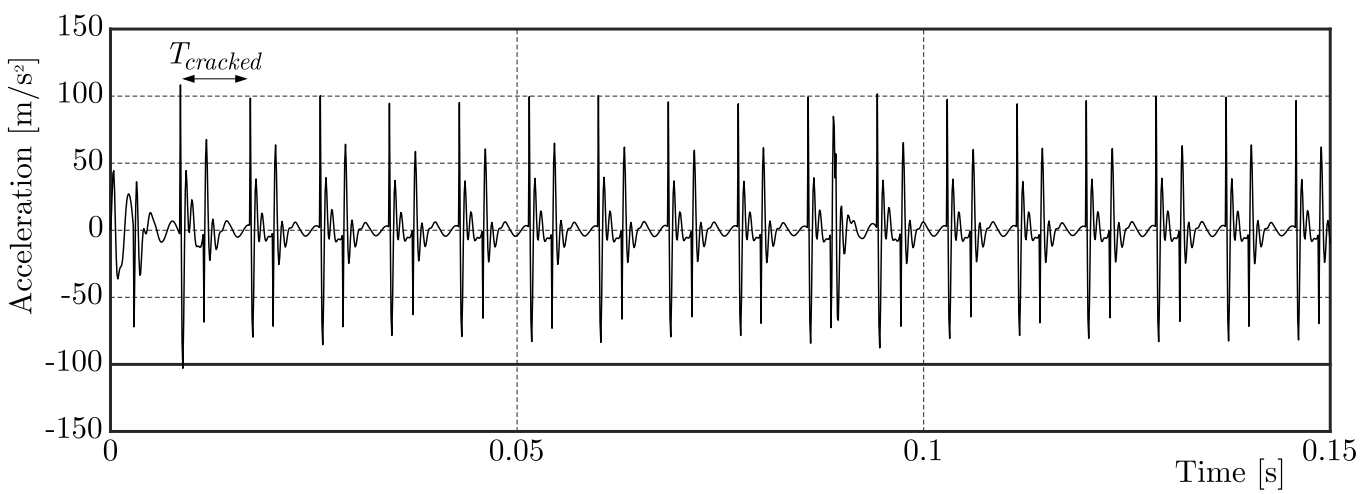

(b)

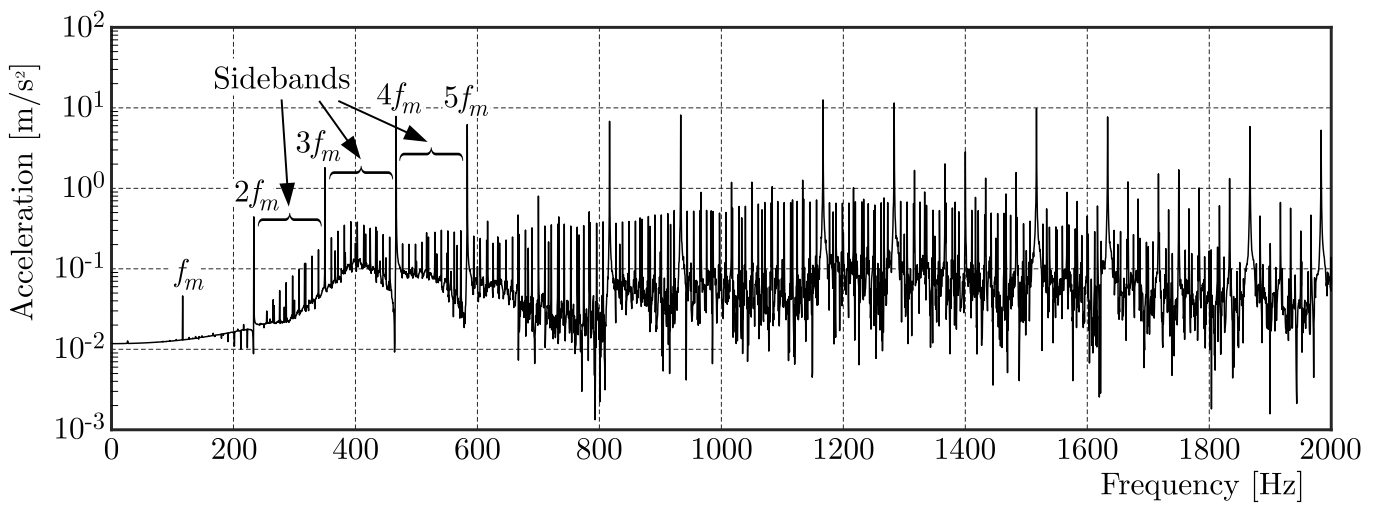

Fig. 8. (a) Time response in the stationary conditions in presence of the cracked tooth, (b) spectrum of acceleration of the cracked tooth in the stationary conditions

3. For each iteration

$$
\begin{aligned}
& \widehat{\mathbf{K}}=\mathbf{K}(t)+\mathbf{K}_{s}+a_{0} \mathbf{M}+a_{0}\left(\mathbf{C}_{m e s h}+\mathbf{C}_{s}\right) \\
& \mathbf{q}_{t+\Delta t}=\widehat{\mathbf{K}}^{-1}\left[\mathbf{F}_{t+\Delta t}+\mathbf{M}\left(a_{0} \mathbf{q}_{t}+a_{2} \dot{\mathbf{q}}_{t}+a_{3} \ddot{\mathbf{q}}_{t}\right)+\left(\mathbf{C}_{m e s h}+\mathbf{C}_{s}\right)\left(a_{1} \mathbf{q}_{t}+a_{4} \dot{\mathbf{q}}_{t}+a_{5} \ddot{\mathbf{q}}_{t}\right)\right] \\
& \ddot{\mathbf{q}}_{t+\Delta t}=a_{0}\left(\mathbf{q}_{t+\Delta t}-\mathbf{q}_{t}\right)-a_{2} \dot{\mathbf{q}}_{t}-a_{2} \ddot{\mathbf{q}}_{t}
\end{aligned}
$$

Figure 6 shows periodic behavior of the bearing displacement of the second block. Its periodicity corresponds to the acyclism period. In the zoomed figure, the dotted circles mark small oscillations resulting from the influence of the tooth contact conditions. These oscillations are modulated by the acyclism effect.

The acceleration signal of the bearing of the second block $\left(X_{2}\right)$ is shown in Fig. 7a, and it is zoomed in Fig. 7b. This signal is modulated by the acyclism and the cracked tooth defect.

In order to study the contribution of each two excitations, new simulations are added. Figures $7 \mathrm{~b}$ and $8 \mathrm{a}$ show respectively the case of a healthy gearbox excited with acyclism and the stationary conditions in presence of the cracked tooth with the same severity. In fact, the shape of acceleration of the healthy gearbox excited with acyclism (Fig. 7b) agrees with the experimental signal of the unloaded gear acceleration recorded by Barthod et al. (2007a,b).

Figure 8a shows acceleration of the case of a constant load and speed (stationary case) in presence of the cracked tooth with the same severity. In this figure (Fig. 8a), it is shown that distinct impulses, with approximate amplitude $100 \mathrm{~m} / \mathrm{s}^{2}$ representing the mating of the cracked tooth, appear and the time interval between every two adjacent impulses is exactly equal to the rotating period of the driven gear because the influence caused by the cracked tooth repeats only once in a revolution of the driven gear. This behavior in the case of the cracked tooth gearbox 
has proved by Ma et al. (2015) and Fakhfakh et al. (2005) who confirmed experimentally the apparition of sidebands around the gear mesh stiffness and its harmonics as shown in Fig. 8b.

Two zoomed graphs around $[0.3 \mathrm{~s}-0.6 \mathrm{~s}]$ and $[0.9 \mathrm{~s}-0.11 \mathrm{~s}]$ in both case studies (Fig. 7a) and the case of the healthy gearbox excited with acyclism (Fig. 7b) are shown. Comparing the zoomed graphs in each time interval, we can identify the peaks corresponding to the crack defect with nearly the same amplitude but with low energy, observing that the acyclism effect dominates over the amplitude of the time response.

Spectral analysis is one of the most widely used techniques. Indeed, analysis of the spectrum of acceleration on the bearing of the second block $\left(X_{2}\right)$ can provide information about their state but only the eigen frequencies of the system $f_{i}$ which are listed in Table 2 and the meshing frequencies appear in Fig. 9.

Table 2. Eigen frequencies $f_{s}[\mathrm{~Hz}](s=1,2, \ldots, 12)$ of the studied system

\begin{tabular}{|c|c|c|c|c|c|}
\hline$f_{1}$ & $f_{2}$ & $f_{3}$ & $f_{4}$ & $f_{5}$ & $f_{6}$ \\
\hline \hline 0 & 26.5 & 411.2 & 1298.2 & 1298.6 & 1299 \\
\hline$f_{7}$ & $f_{8}$ & $f_{9}$ & $f_{10}$ & $f_{11}$ & $f_{12}$ \\
\hline \hline 1475.5 & 1638.9 & 1638.9 & 2344.4 & 2624.8 & 3821.2 \\
\hline
\end{tabular}
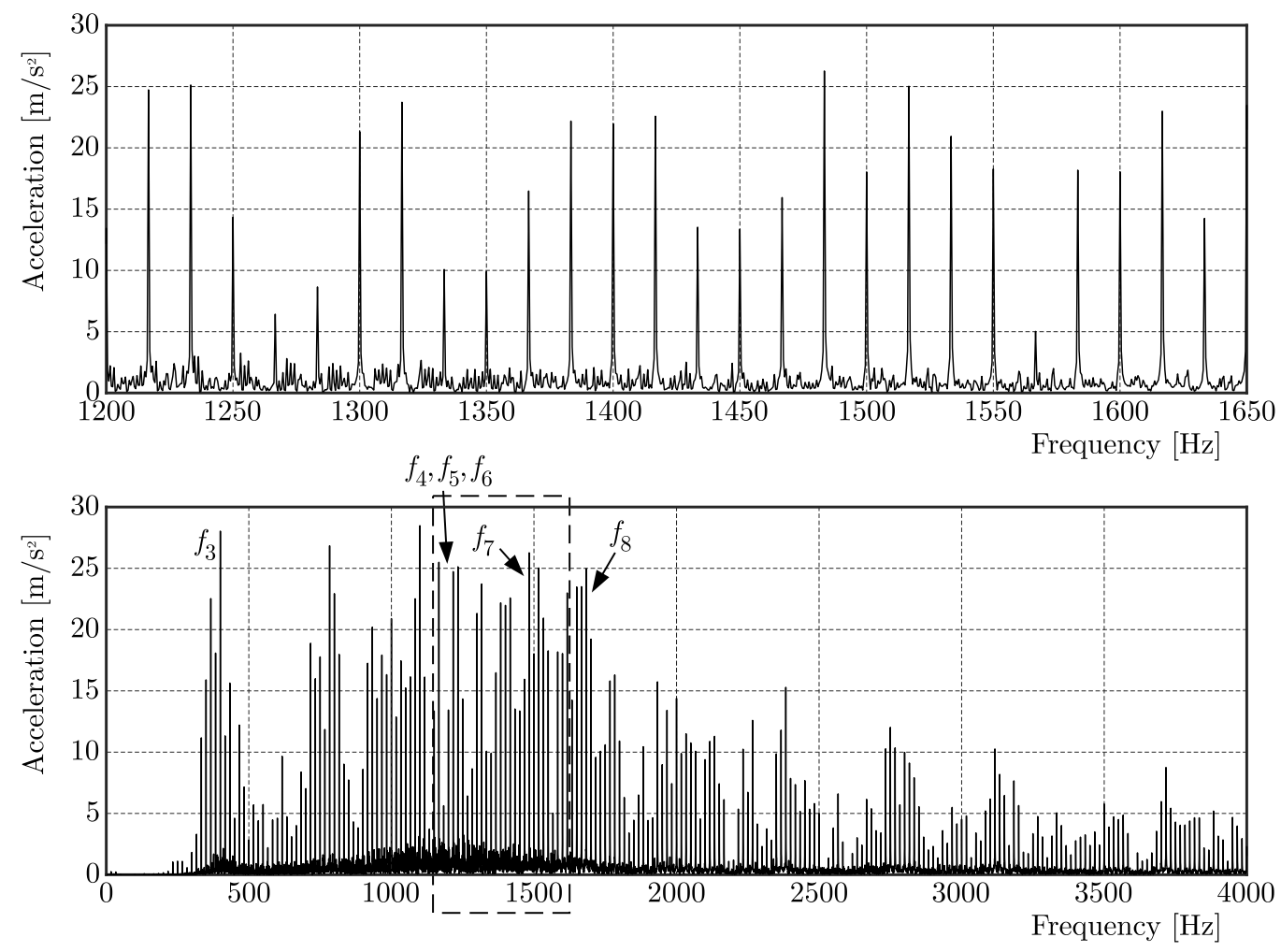

Fig. 9. The spectrum of acceleration on the bearing of the second block $\left(X_{2}\right)$

The spectrum of acceleration is not suitable to analyze the dynamic behavior of the gearbox running under a cyclo-stationary regime and in the presence of the cracked tooth defect. So, we used two signal techniques which are joint time frequency analysis and envelope spectrum of the acceleration signal in order to characterize the cracked tooth faults in the case of the acyclism regime.

Figure 10 represents the Wigner-Ville distribution of the acceleration on the bearing of the second block $\left(X_{2}\right)$ in order to analyze the cyclo-stationary signal. 

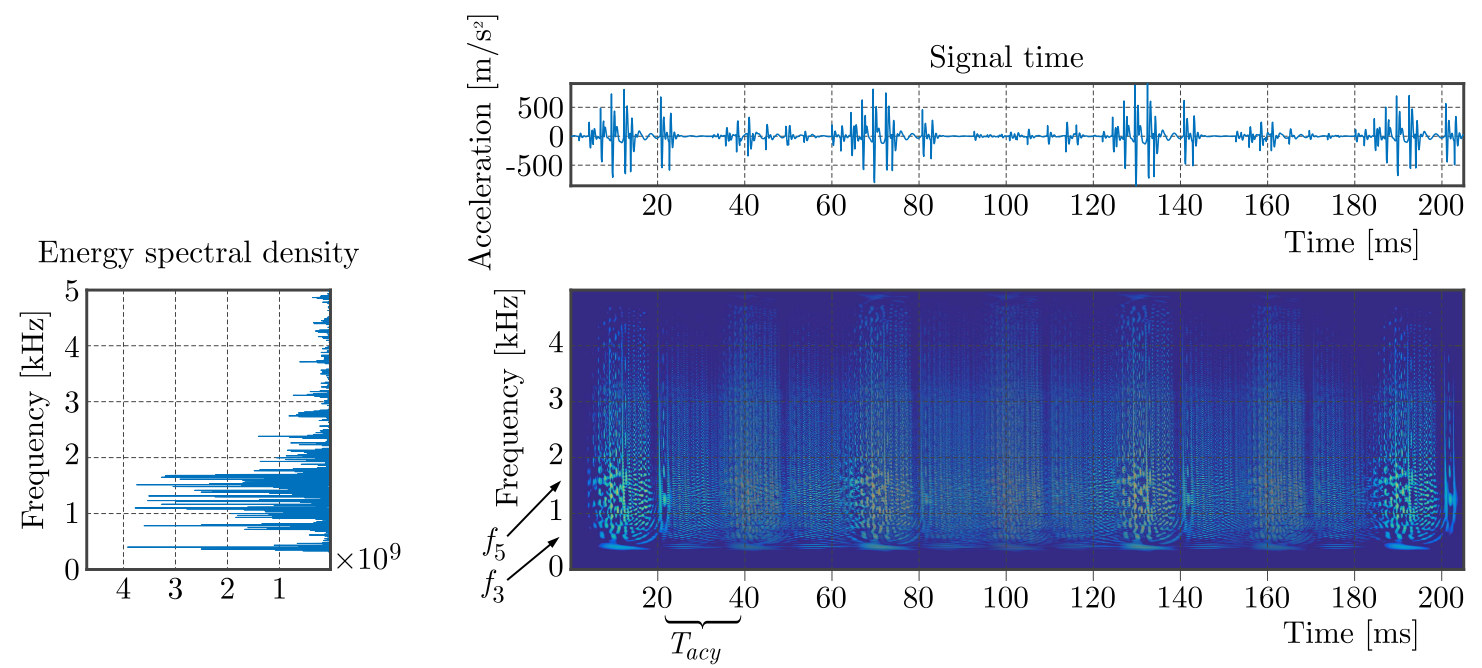

Fig. 10. Distribution of the Wigner-Ville of the acceleration on the bearing of the second block $\left(X_{2}\right)$

Due to the acyclism regime, we can note from the previous figure the variability of the internal source of excitation, which is the meshing frequency and its harmonics, and horizontal lines representing the eigen frequencies of the mechanical system. Nevertheless, the effect of the tooth defect is not observed.

Figure 11 shows the envelope spectrum of the acceleration signal of the bearing of the second block.
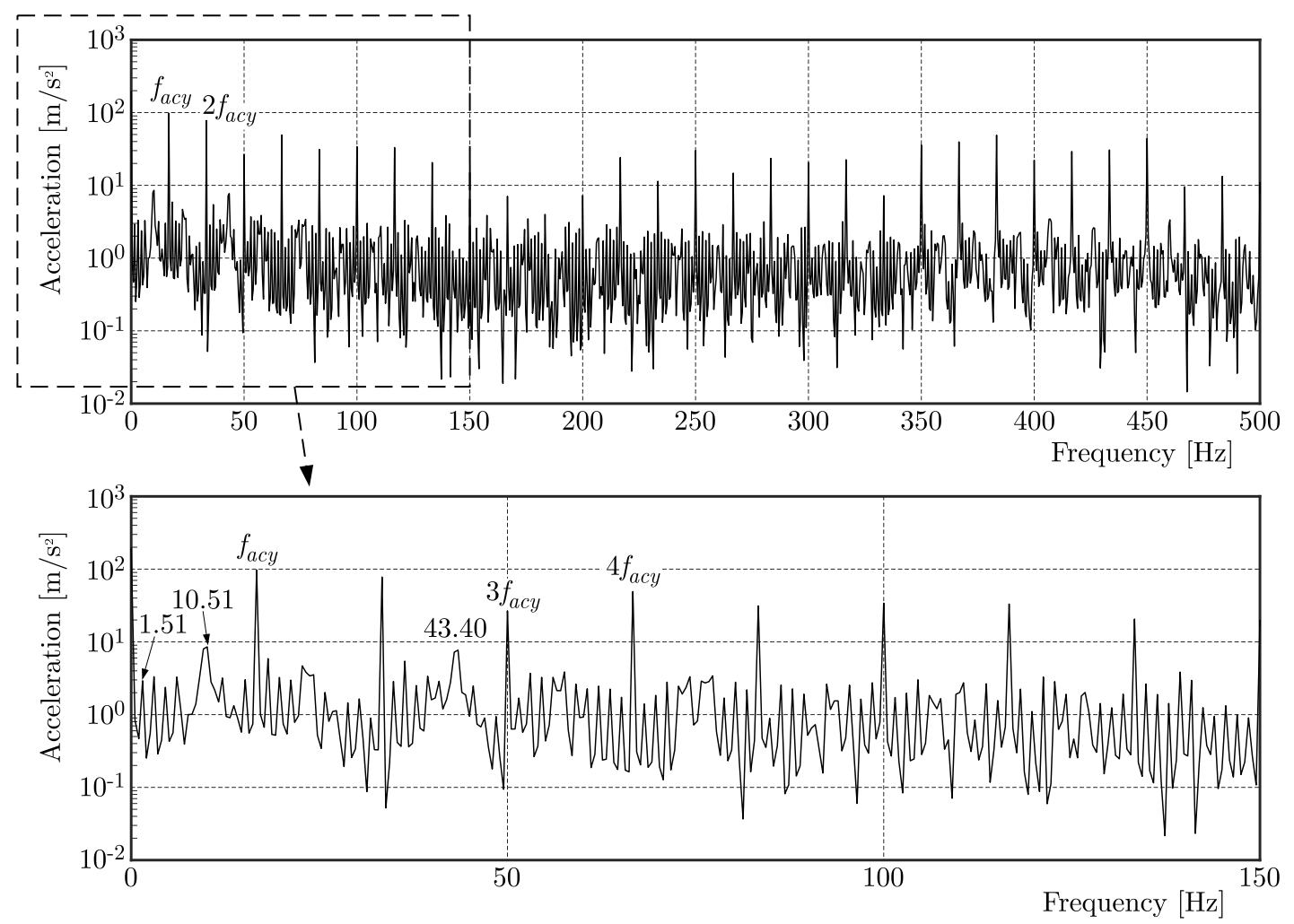

Fig. 11. Spectrum envelope of the acceleration signal in the $X$ direction of the second block

The spectrum envelope shows several harmonics of the frequency of acyclism $\left(f_{a c y}=\right.$ $16.67 \mathrm{~Hz})$.

The zoom on the frequency band $[0 \mathrm{~Hz}-150 \mathrm{~Hz}]$ is shown also in Fig. 11. 
We note that the diesel engine generates a variable speed where its frequencies of rotation are in the band [967.34 Hz-1032.3 Hz], the gear mesh frequency varies from $112.85 \mathrm{~Hz}$ to $120.43 \mathrm{~Hz}$ and the frequency of the defect varies from $10.26 \mathrm{~Hz}$ to $10.95 \mathrm{~Hz}$. So, the two peaks located at $10.51 \mathrm{~Hz}$ and $43.4 \mathrm{~Hz}$ are due to the cracked tooth. In addition, sidebands appear around the frequency of acyclism and its harmonics. The frequency of sidebands is $f_{\text {acy }} / Z_{31}=1.51 \mathrm{~Hz}$.

The angular speed of the pinion is equal to the speed of the diesel engine and the greatest common divisor of the number of teeth of the pinion and the defected wheel gear $\left(Z_{22}\right.$ and $\left.Z_{31}\right)$ is one. So, the appearance of defect happens with the same way each ${ }_{T} a c y \times Z_{31}$ period and the frequency $f_{a c y} / Z_{31}$.

\section{Conclusion}

In this paper, the dynamic response of a mechanical system composed of a cracked gearbox and a flexible coupling is studied under the acyclism regime generated by a combustion engine. This regime generates variable speed which is modeled as a multi-harmonic function and a variable torque, which is computed for the case of known variation of the pressure inside cylinders. A cracked tooth in the gear is introduced by lowering of the gear mesh stiffness for a particular case where the greatest common divisor between the pinion and gear teeth numbers is equal to one. The effects of the cracked tooth and the acyclism are studied independently, and the obtained results agree with experiments in literature.

In the studied system running under a cyclo-stationary regime, the frequency of the cracked defect is independent of the acyclism regime. Time acceleration and spectral analysis fail to detect the frequencies of the defects and the acyclism. The Wigner-Ville distribution and the spectrum envelope of the dynamic response are used to provide information about their state. In fact, the meshing frequency and its harmonics variability in each acyclism period are observed in a joint time-frequency presentation, and the apparition of sidebands around the frequency of acyclism on the envelope spectrum proves the influence of the cracked tooth defect on the wheel gear which occurs with the same acyclism period multiplied by the number of teeth of the gear wheel.

In the future works, we propose to carry out experiments in order to confirm the theoretical analyses of the combined effects.

\section{References}

1. Bartelmus W., 2001, Gearbox dynamic modelling, Journal of Theoretical and Applied Mechanics, 39, 4, 989-999

2. Barthod M., Hayne B., Tebec J.-L., Pin J.-C., 2007a, Experimental study of dynamic and noise produced by a gearing excited by a multi-harmonic excitation, Applied Acoustics, 68, 982-1002

3. Barthod M., Hayne B., Tebec J.-L., Pin J.-C., 2007b, Experimental study of gear rattle excited by a multi-harmonic excitation, Applied Acoustics, 68, 1003-1025

4. Baudin S., Rémond D., Antoni J., Sauvage O., 2016, Non-intrusive rattle noise detection in non-stationary conditions by an angle/time cyclostationary approach, Journal of Sound and Vibration, 366, 501-513, DOI 10.1016/j.jsv.2015.11.044

5. Chani F., Fakhfakh T., Haddar M., 2009, Analytical modelling of spur gear tooth crack and influence on gearmesh stiffness, European Journal of Mechanics A/Solids, 28, 461-468

6. Dhatт G., Tоuzot G., 1984, Une présentation de la méthode des éléments finis (in French), Paris, Editions Maloine S.A. 
7. Driss Y., Hammami A., Walha L., Haddar M., 2014, Effects of gear mesh fluctuation and defaults on the dynamic behavior of two-stage straight bevel system, Mechanism and Machine Theory, 82, 71-86

8. Fakhfakh T., ChaAri F., Haddar M., 2005, Numerical and experimental analysis of a gear system with teeth defects, International Journal of Advanced Manufacturing Technology, 25, $542-550$

9. Ghorbel A., Zghal B., Abdennadher M., Walha L., Haddar M., 2018, Effect of the gear local damage and profile error of the gear on the drivetrain dynamic response, Journal of Theoretical and Applied Mechanics, 56, 3, 765-779

10. Hammami A., Fernandez A., Viadero F., Chaari F., Haddar M., 2015, Modal analysis of back-to-back planetary gear: experiments and correlation against lumped parameter model, Journal of Theoretical and Applied Mechanics, 53, 1, 125-138

11. Hmida A., Hammami A., Khabou M.T., ChaAri F., Haddar M., 2017, Effect of elastic coupling on the modal characteristics of spur gearbox system, Applied Acoustics, http://dx.doi.org/10.1016/j.apacoust.2017.06.013

12. Hmida A., Hammami A., Khabou M.T., ChaAri F., Haddar M., 2018, Dynamic behavior of spur gearbox with elastic coupling in the presence of eccentricity defect under acyclism regime, [In:] Rotating Machinery and Signal Processing, A. Felkaoui, F. Chaari, M. Haddar (Edit.), Springer, $123-132$

13. Khabou M.T., Bouchanla N., Chanri F., Fakhfakh T., Haddar M., 2011, Study of a spur gear dynamic behavior in transient regime, Mechanical Systems and Signal Processing, 25, 3089-3101

14. Kramer E., 1993, Dynamics of Rotors and Foundations, New York, Springer-Verlag

15. Ligier J.L., Baron E., 2002, Acyclism and Vibrations: Applications to Combustion Engine and Tranmissions (in French), vol. 1, Editions TECHNIP, Paris

16. ŁuCZKo J., 2008, Chaotic vibrations in gear mesh systems, Journal of Theoretical and Applied Mechanics, 46, 4, 879-896

17. Ma H., Song R., PAng X., Wen B., 2014, Fault feature analysis of a cracked gear coupled rotor system, Mathematical Problems in Engineering, 2014, Article ID 832192, 22 p.

18. Ma H., Zeng J., Feng R., Pang X., Wang Q., Wen B., 2015, Review on dynamics of cracked gear systems, Engineering Failure Analysis, 55, 224-245

19. Nelson H.D., CRAndall S.H., 1992, Analytic prediction of rotor dynamic response, [In:] Handbook of Rotor Dynamics F.E. Ehrich (Edit.), McGraw-Hill Inc., New York

20. PARK S., Kim S., Choi J.H., 2018, Gear fault diagnosis using transmission error and ensemble empirical mode decomposition, Mechanical Systems and Signal Processing, 108, 262-275

21. Saxena A., Chouksey M., Parey A., 2017, Effect of mesh stiffness of healthy and cracked gear tooth on modal and frequency response characteristics of geared rotor system, Mechanism and Machine Theory, 107, 261-273

22. SiKA G., VELEX P., 2008, Instability analysis in oscillators with velocity-modulated time-varying stiffness - Applications to gears submitted to engine speed fluctuations, Journal of Sound and Vibration, 318, 166-175

23. Tadeo A.T., Cavalca K.L., 2003, A comparison of flexible coupling models for updating in rotating machinery response, Journal of the Brazilian Society of Mechanical Sciences and Engineering, XXV, 3, 235-246

24. Tadeo A.T., Cavalca K.L., Brennan M.J., 2011, Dynamic characterization of a mechanical coupling for a rotating shaft, Proceedings of the Institution of Mechanical Engineers, Part C: Journal of Mechanical Engineering Science, 225, 604-616 